
\title{
$\begin{array}{ll}\text { Research Square } & \begin{array}{l}\text { Preprints are preliminary reports that have not undergone peer review. } \\ \text { They should not be considered conclusive, used to inform clinical practice, } \\ \text { or referenced by the media as validated information. }\end{array}\end{array}$
}

\section{The City in the Tropics: Lizard Community Structure and Spatial Resource Use Along an Habitat Gradient of the Dahomey Gap (West Africa)}

Luca Luiselli ( $\sim$ lucamaria.Iuiselli@uniroma3.it)

Rivers State University of Science and Technology https://orcid.org/0000-0001-6878-2916

Daniele Dendi

Rivers State University of Science and Technology

Fabio Petrozzi

Rivers State University of Science and Technology

Gabriel Hoinsoudé Segniagbeto

Universite de Lomé Faculté des Sciences: Universite de Lome Faculte des Sciences

\section{Research Article}

Keywords: Sauria, Togo, niche partitioning, habitat use, community ecology, ecological gradients

Posted Date: April 14th, 2021

DOl: https://doi.org/10.21203/rs.3.rs-310688/v1

License: (c) (i) This work is licensed under a Creative Commons Attribution 4.0 International License. Read Full License 


\section{Abstract}

Studies on habitat gradients are particularly interesting for the community ecology theory, but almost no investigation has been carried out on community structure of any vertebrate groups along gradients of habitat that were modified by humans in historical or prehistorical times, such as for instance the Dahomey Gap in West Africa. Here, we analyze the community structure of lizards in suburban Lomé (Togo) and in comparison with nearby savannah and forest sites, with a suite of statistical methods. Overall, we recorded 25 lizard species, with a heavy reduction in species richness from forest (18 taxa) to savannah (13) and suburbs (9). $24 \%$ of the species occurred in all habitat types, $40 \%$ exclusively in forest, and only two were exclusive of suburban habitats. Suburban habitat types were relatively homogeneous in terms of number of observed species (maximum number of taxa per habitat $=6$ ). There were significant interspecific differences in both substratum type preferences and vertical spatial niche by species, but with no evidence of a nonrandom niche partitioning pattern, and hence with a competitively assembled community structure. There was a nonrandom "clustered" distribution of the various species along the available resource categories, thus indicating that species-specific preferences instead of community-driven mechanisms are more likely to explain the observed patterns. We concluded that lizard communities in tropical cities are (i) less species-rich than in the surrounding more natural habitats, (ii) usually clustered into specific habitat/substratum types (often artificial ones), and (iii) not assembled through competitive interactions.

\section{Introduction}

Studies on habitat gradients are particularly interesting for the community ecology theory because the environmental continuum may be a useful axis for understanding how attributes of individuals do generate structure at the level of the community (e.g. see Wellborn et al. 1996; Pillsbury and Miller 2008; Khatiwada et al. 2019). It has been shown that community structure across a given gradient may be determined by both physical factors limiting the potential breadth of species distributions (for instance, proximate eco-physiological performances; see Barbault 1991; or habitat characteristics, e.g. Avila et al. 2017) and biotic effects mediated by ecological interactions, such as predation (Nurminen et al. 2018; Freestone et al. 2020) and interspecific competition (Pianka 1986; Salinas-Ramos et al. 2020; Powell et al. 2021).

Most studies on community structure along tropical habitat gradients have focused so far on habitats that have been modified by humans during recent times, for instance burnt versus non-burnt areas (Akani et al. 2018; Costa et al. 2020) or forest-plantation mosaics (Palmeirim et al. 2017; Supsup et al. 2020). However, almost no investigation has been carried out on community structure of any vertebrate groups along habitat gradients that were modified by humans in historical or prehistorical times, despite these studies may be important for a better under standing of the community dynamics along habitat gradients. In this regard, the Dahomey Gap in West Africa may offer a excellent scenario where to perform such studies. The Dahomey Gap is a savannah-like vegetation zone that extends all the way to the coast in Benin, Togo, and Ghana, thus separating the forest zone that covers much of the south of the region into two separate forested regions: the Upper Guinean forests and the Lower Guinean forests (Demenou et al. 2018). The Dahomey Gap has been created, according to some studies, by deforestation during the late Holocene, whereas for other researchers it should be a natural transitional vegetation zone between forest and savannah (Demenou et al. 2018). Anyway, now the Dahomey Gap is also characterized by the presence of a myriad of urban centres, with Accra (capital of Ghana), Lomé (capital of Togo) and Cotonou/Porto Novo (Benin) being the largest urban agglomerates.

In this study, we analyze the community composition of sympatric lizards along a habitat gradient, forest-savannah-suburbs (hereby FSS), in south-western Togo, inside the Dahomey Gap of West Africa. We will focus (i) on the taxonomical composition and species richness of lizards within each habitat type, and (ii) on their resource partitioning patterns along the spatial niche axis with regard to the suburban habitat. We selected the suburban habitat for the detailed resource partitioning study because this is the simplest habitat type of the Dahomey Gap in terms of number of sympatric species, thus allowing a easier quantitative assessment and a better understanding of the community dynamics.

More specifically, in the present paper, we examine the following key questions:

1. Are there any species richness differences among lizard assemblages inhabiting the various habitats in the FSS gradient? This question is relevant because there are empirical evidences that tropical forest communities are more species-rich than savannahs or deforested areas (Estrada et al. 1993; Addai and Baidoo 2013; Yeo et al. 2017; Schyra et al. 2019), but quantitative data are not available for the Dahomey Gap region in West Africa.

2. If so, are the inter-habitat differences in species richness due to proximate ecological factors (i.e. recent events of local deforestation) or to broad historical/biogeographical events at the West African scale? This is important because the Dahomey Gap has been considered an anthropogenic vegetation zone that originated thousands year ago (lloh et al. 2017; Demenou et al. 2018; Leaché et al. 2020), so it is possible that not only proximate factors may influence actual community structure.

3. Focusing on the ecologically simplest habitat type (in terms of species richness) in the gradient, what are the main assembly rules of the lizard assemblage? That is: is interspecific competition for the spatial niche an important determinant of the community structure in the simplest habitat type of the FSS gradient? This aspect is relevant because it is easier to detect interspecific competition mechanisms in simple than in complex arenas, and thus a relatively simple natural scenario may help considerably our understanding on this issue.

\section{Materials And Methods Study areas and field protocol}

In order to compare community composition of lizards across a gradient of habitat alteration (FSS), we used data from Segniagbeto et al. (2015) for forest and forest-derived savannah, supplemented by original opportunistic field observations (years 2013-2020), and compared these data with those originally collected by us in the suburbs of Lomé (see below). The map of southern Togo, showing the various study areas, is given in Fig. 1. For forest, we considered 
the presence data of lizards for Missahohé, Agome Yo, Kpalimé and Agou, i.e. four hilly, adjacent sites situated nearby the border with Ghana in south-western Togo. For forest-derived savannah,we considered the presence data of lizards at Tsévié, Tgblekope and Agoé, also situated in the south-western Togo.

The field study at the urban area was carried out in July-August 2013 and in July-August 2014 in a suburban area of Lomé (Baguida), the capital city of Togo, West Africa. Baguida is a residential area situated along the coast, at the western periphery of Lomé, nearby the city port and along the highway connecting Togo with Benin. The climate of this area is tropical, with dry season from October to March, wet season from April to September, but with a short phase of relative rain shortfall during August.

Suburban lizards were searched for along random transects, walked slowly and by two-three researchers, passing through the Baguida landscapes, from about 0900-1200hrs and 2000-2200hrs, for a total of 21 field days in 2013 and 23 days in 2014. Visual Encounter Survey (VES) methodology was applied, and each lizard was observed at a distance ranging 10-150 cm. During night hours, we used a torch (model Weltool T10) to examine the various substratum types and recording the lizards. We considered in the analyses only the above-ground active individuals, so, we did not consider those lizards (mainly Agama agama) that were observed while sleeping perched on walls, trees or other substrates.

Each observed lizard was identified to species and sex; however, $H$. angulatus and $H$. mabouia were pooled due to their difficult discrimination in the field. We recorded the habitat characteristics of each lizard individual along a horizontal and a vertical spatial axes. In order to evaluate the horizontal spatial resource use, we recorded the substratum where each individual was recorded. Lizard sightings were assigned to one of the following six different substratum types $\wedge 1$ ) cement/asphalt, (2) grass, (3) trees/wood, (4) sand, (5) bushes, and (6) stone-piles. The relative availability of each substratum type was determined by eye by inspecting the relative area occupied by each habitat type in 1000 random spots of $5 \times 5 \mathrm{~m}$ that were selected along the surveyed area. $\mathrm{N}$ order to evaluate the horizontal spatial resource use, we determined the height from the ground of each lizard individual at the sighting time. We defined five height categories: (a) on the ground (up to $10 \mathrm{~cm}$ height); (b) 11-50 cm height; (c) 51-100 cm height; (d) 101-150 cm height; (e) >150 cm height.

\section{Statistical analyses}

Comparisons of lizard community compositions among the three FSS gradient habitats were made just qualitatively as there were no sufficient quantitative data in Segniagbeto et al. (2015) to allow any statistical analysis. Concerning the XXXystemat lizard community, the differences in the frequencies of observed lizards by species and by substratum type, as well as within species (i.e. males versus females versus juveniles) and by substratum type, were assessed by contingency table $\chi^{2}$ test. Pearson's correlation coefficient was used to analyze the correlation between substratum type availability (independent variable) and number of observed lizards by species (dependent variable). When running the above-mentioned analyses, we considered that, in order to process the data statistically, the sufficient number of individuals per species was 30 . Thus, we did not analyze the data by contingency tables and correlations for those species with less than 30 sightings.

Table 2

Raw data of the lizard sightings at the suburban area, divided by species and by substratum type, at Baguida (Lomé), Togo.

\begin{tabular}{|c|c|c|c|c|c|c|c|c|c|c|}
\hline & & $\begin{array}{l}\text { A. } \\
\text { agama }\end{array}$ & $\begin{array}{l}\text { A. } \\
\text { agama }\end{array}$ & $\begin{array}{l}\text { A. } \\
\text { agama }\end{array}$ & $\begin{array}{l}\text { T. } \\
\text { quinquetaeniata }\end{array}$ & $\begin{array}{l}T \text {. } \\
\text { quinquetaeniata }\end{array}$ & $\begin{array}{l}\text { T. } \\
\text { quinquetaeniata }\end{array}$ & $\begin{array}{l}T . \\
\text { maculilabris }\end{array}$ & $\begin{array}{l}T . \\
\text { perrotetii }\end{array}$ & $\begin{array}{l}\text { Chan } \\
\text { gracil }\end{array}$ \\
\hline substratum & $\begin{array}{l}\% \\
\text { availability }\end{array}$ & males & females & juveniles & males & females & juveniles & & & \\
\hline cement & 46 & 26 & 48 & 40 & 0 & 4 & 0 & 2 & 0 & 0 \\
\hline grass & 45 & 48 & 62 & 86 & 5 & 9 & 0 & 0 & 0 & 0 \\
\hline bushes & 1,4 & 7 & 5 & 4 & 8 & 10 & 0 & 0 & 0 & 0 \\
\hline sand & 7 & 4 & 6 & 5 & 13 & 17 & 0 & 0 & 0 & 0 \\
\hline trees/wood & 0,5 & 2 & 1 & 0 & 17 & 23 & 7 & 0 & 2 & 1 \\
\hline stone piles & 0,1 & 0 & 5 & 3 & 1 & 1 & 7 & 2 & 6 & 0 \\
\hline total & 100 & 87 & 127 & 138 & 44 & 64 & 14 & 0 & 0 & 0 \\
\hline
\end{tabular}

In order to differentiate the various types of substrates in terms of their quantitative lizard community composition, we used a One-Way Analysis of Similarities (ANOSIM). ANOSIM is roughly analogous to an ANOVA in which the univariate response variable is replaced by a dissimilarity matrix, i.e. with distances that were converted to ranks (Clarke 1993). Significance was computed by permutation of group membership, with 9,999 replicates, and Bray-Curtis was used as distance measure. Sequential Bonferroni correction was used for post-hoc comparisons of pairwise ANOSIMs between all pairs of groups.

We calculated Chao-1 index in order to predict the theoretical number of species that can be expected to use each substratum type on the basis of the sampling regime. In addition, the following univariate community diversity metrics were calculated for each substratum type: (i) Species richness (total number of species recorded at each site); (ii) Dominance (D); (iii) Simpson index (S) S = 1 - D; (iv) Shannon entropy index (H'; Shannon and Weaver 1963) and (v) Evenness (e), calculated by Buzan and Gibson's formula (Magurran 1988). For each diversity metric, we also generated upper and lower $95 \%$ confidence intervals by performing a bootstrap analysis with 9999 random samples, each with the same total number of individuals as in each original sample generated (Harper 1999).

Niche breadth (B) in resource uses was assessed by Simpson's (1949) index. In order to evaluate the "structure" (sensu Gotelli and Entsminger 2003) of the lizard community in terms of substratum use and height of perches, we firstly calculated the similarity XXXystema species/population groups by Pianka's (1986) symmetric equation (with 0 indicating no similarity and 1 total similarity), and then performed a statistical simulation study. Indeed, to assess whether 
the various observed overlap values between species/population group pairs occurred by chance, we randomized the original species utilization matrices by shuffling the original values among the resource states by using the randomization algorithms RA2 and RA3 (Lawlor 1980), with 30,000 random Monte Carlo permutations generated by Ecosim software. RA2 tests for structure in the generalist-specialist nature of the resource utilization matrix by conserving guild structure, but destroying observed niche breadth (Gotelli and Graves 1996). RA3 tests for guild structure by conserving niche breadth for each species, but destroying guild structure manifested by the zero structure of the resource utilization matrix (Gotelli and Graves 1996). If the observed overlaps were significantly lower than the randomized overlaps, there was evidence of community-wide niche partitioning of the analyzed niche dimensions (substratum type and perch height). If the observed overlaps were significantly higher than the randomized overlaps, there was evidence of community-wide convergent use of the niche dimensions (i.e. a "contagion" effect), whereas if observed and randomized overlaps did not differ significantly, the lizard community used the niche dimensions by chance, i.e. randomly. The substratum type availability (\%) was added to the XXXystematicXXX in the Ecosim software.

The pairwise similarity of each lizard species with the availability of each substratum type was assessed by non-metric multidimensional scaling (nMDS), using cosine as similarity measure between items in the item-item matrix. A Principal Component Analysis (PCA) was used to displaying the various lizard species by substratum type in the multivariate space, retaining only factors with eigenvalues $>1$ in the analysis.

\section{Results}

\section{General community characteristics}

Pooling all the study areas, there were 25 lizard species in total, belonging to five different families (Table 1). Comparing the species composition along the FSS gradient, there was a heavy reduction in the species richness, from 18 taxa in the forest to 12 in the savannah up to 9 in the suburbs (Table 1 ). Six species ( $24 \%$ of the total) were found in all habitat types along the gradient, ten (40\%) were found exclusively in forest, four (16\%) only in savannah, two were found in both forest and savannah (8\%), in both forest and suburbs, and in only suburban habitats. This exclusively suburban species were the geckos Ptyodactylus ragazzi, that was recently introduced by merchants of charcoal and firewood transported from the northern regions of Togo (our unpublished observations), and Tarentola ephippiata. These latter species are currently common in some areas of Lomé, for example in the Be-Kpotà sector of the main city centre. 
Table 1

Comparison of species richness along the forest, forest-derived savannah, suburbs gradient in South-Western Togo. 1 = indicates presence of a given species in a given habitat type along the FSS

\begin{tabular}{|c|c|c|c|c|}
\hline Genus & Species & forest & savannah & urban \\
\hline \multicolumn{5}{|l|}{ Scincidae } \\
\hline Trachylepis & affinis & 1 & 1 & \\
\hline Trachylepis & albilabris & 1 & & \\
\hline Trachylepis & maculilabris & 1 & 1 & 1 \\
\hline Trachylepis & perrotetii & 1 & 1 & 1 \\
\hline Trachylepis & polytropis & 1 & & \\
\hline Trachylepis & quinquetaeniata & 1 & 1 & 1 \\
\hline Cophoscincopus & simulans & 1 & & \\
\hline Mochlus & guineensis & 1 & & \\
\hline Panaspis & togoensis & 1 & & \\
\hline \multicolumn{5}{|l|}{ Gekkonidae } \\
\hline Hemidactylus & albituberculatus & & 1 & \\
\hline Hemidactylus & angulatus & 1 & 1 & 1 \\
\hline Hemidactylus & fasciatus & 1 & & \\
\hline Hemidactylus & kyaboboensis & 1 & & \\
\hline Hemidactylus & mabouia & 1 & 1 & 1 \\
\hline Hemidactylus & muriceus & 1 & & \\
\hline Ptyodactylus & ragazzi & & & 1 \\
\hline Tarentola & ephippiata & & & 1 \\
\hline \multicolumn{5}{|l|}{ Agamidae } \\
\hline Agama & agama & 1 & 1 & 1 \\
\hline Agama & sankaranica & & 1 & \\
\hline \multicolumn{5}{|l|}{ Chamaeleonidae } \\
\hline Chamaeleo & gracilis & 1 & 1 & \\
\hline Chamaeleo & necasi & 1 & & \\
\hline Chamaeleo & senegalensis & & 1 & 1 \\
\hline \multicolumn{5}{|l|}{ Varanidae } \\
\hline Varanus & exanthematicus & & 1 & \\
\hline Varanus & niloticus & & 1 & \\
\hline Varanus & ornatus & 1 & & \\
\hline TOTAL & & 18 & 13 & 9 \\
\hline
\end{tabular}

There were significant differences in the frequency of species by ecological niche (arboreal/climbers; arboreal-terrestrial; terrestrial; subterranean) across the FSS gradient (contingency table: $\chi^{2}=23.4, \mathrm{df}=6, \mathrm{P}<0.001$ ), although arboreal-terrestrial and arboreal/climbers were dominant in all habitat types (Fig. 2 ). The forest lizard community had however a higher breadth of utilized niches compared to the other two habitats (Fig. 2).

\section{Community structure in the suburban area}

In the suburban site, during our surveys we observed a total of 611 individuals belonging to 6 species of lizards. Three of the observed species were Scincidae ( 2 individuals of Trachylepis maculilabris, 8 Trachylepis perrotetii, and 122 were Trachylepis quinquetaeniata), one Agamidae (352 individuals of Agama agama), one Gekkonidae (126 individuals of Hemidactylus sp.), and one Chamaeleonidae (one individual of Chamaeleo senegalensis). Only three species were observed in sufficient number for statistical analysis to determine their niche characteristics patterns: A. agama, T. quinquetaeniata and Hemidactylus sp. The former two species were observed only during the period 0900-1200 hrs, whereas Hemidactylus sp. mainly during the period 2000-2200 hrs, with four individuals sighted in the morning sampling. 
Species richness was adequately sampled within each habitat type, as revealed by the plateau phase reached by the respective saturation curves (Online Supplementary Figure S1). Habitat types were relatively homogeneous in terms of number of observed species, with the highest number $(n=6)$ being observed in bushes (Table 2). Chao-1 estimated that the maximum number expectable per habitat type is 7 (Table 3 ). In terms of diversity metrics (calculated from the number of individuals by lizard species sighted on each substratum), the various substrates showed relatively similar values, with bushes and trees/wood being used by a slightly higher diversity of species and with a slightly higher evenness than the other substrates (Table 3). However, there were no statistically significant differences among substrates for any of the diversity metrics using ANOSIM (mean rank within substratum types = 29.46; mean rank between substratum types $=37.6 ; R=0.05$, at least $P>0.155$ in all metrics).

Table 3

Mean values of diversity metrics, with upper and lower $95 \%$ confidence intervals $(\mathrm{Cl})$, for the various substratum types surveyed in Baguida (Lomé), Togo.Values are calculated on the basis of the number of lizard individuals by species that were observed in each substratum type during the field surveys.

\begin{tabular}{|lllllllll|}
\hline & Species richness & Individuals & Dominance & Simpson & Shannon & Evenness & Chao- 1 \\
\hline cement & 3 & 178 & 0.547 & 0.453 & 0.713 & 0.68 & 3 \\
\hline Lower $\mathrm{Cl}$ & 3 & 178 & 0.3541 & 0.5472 & 0.9604 & 0.4867 & 3 \\
\hline Upper Cl & 6 & 178 & 0.4523 & 0.6454 & 1.162 & 0.8652 & 7 \\
\hline Grass & 3 & 179 & 0.7591 & 0.2409 & 0.4851 & 0.5415 & 3 \\
\hline Lower Cl & 3 & 179 & 0.3556 & 0.5412 & 0.9555 & 0.4938 & 3 \\
\hline Upper Cl & 6 & 179 & 0.4588 & 0.6442 & 1.166 & 0.8845 & 7 \\
\hline trees/wood & 3 & 76 & 0.4058 & 0.5942 & 0.9969 & 0.9033 & 3 \\
\hline Lower Cl & 3 & 76 & 0.3393 & 0.5083 & 0.8908 & 0.5555 & 3 \\
\hline Upper $\mathrm{Cl}$ & 5 & 76 & 0.4917 & 0.6586 & 1.196 & 0.9428 & 6 \\
\hline Sand & 3 & 49 & 0.4969 & 0.5031 & 0.7982 & 0.7405 & 3 \\
\hline Lower $\mathrm{Cl}$ & 3 & 49 & 0.3294 & 0.4715 & 0.8477 & 0.5827 & 3 \\
\hline Upper $\mathrm{Cl}$ & 5 & 49 & 0.5277 & 0.6706 & 1.215 & 0.9612 & 6 \\
\hline Bushes & 6 & 71 & 0.4767 & 0.5233 & 1.077 & 0.4891 & 6 \\
\hline Lower Cl & 3 & 71 & 0.3402 & 0.4983 & 0.8908 & 0.5569 & 3 \\
\hline Upper $\mathrm{Cl}$ & 5 & 71 & 0.5013 & 0.6594 & 1.182 & 0.9513 & 6 \\
\hline stone piles & 3 & 25 & 0.3344 & 0.6656 & 1.097 & 0.9984 & 3 \\
\hline Lower $\mathrm{Cl}$ & 3 & 25 & 0.3184 & 0.3904 & 0.7038 & 0.5911 & 3 \\
\hline Upper Cl & 5 & 0.6096 & 0.6816 & 1.241 & 0.9784 & 6 \\
\hline
\end{tabular}

\section{Suburban lizards: horizontal niche resource use}

The synopsis of the observations by species and by substratum type, and in relation to the relative availability of each substratum, is given in Table 2 . The three species used the various substrates in a significantly different way $\left(\chi^{2}=225.68, d f=5, P=0.00001\right)$, with $A$. agama being observed mainly in cement and grass, $T$. quinquetaeniata mainly in bushes and sand, and $H$. angulatus in cement and trees/wood. Within species, there were neither intersexual $\left(\chi^{2}=7.2, \mathrm{df}=\right.$ $5, \mathrm{P}=0.209)$ nor adults versus juveniles $\left(\chi^{2}=8.6, \mathrm{df}=5, \mathrm{P}=0.111\right)$ differences in $A$. agama; similarly, there were no significant intersexual differences in $T$. quinquetaeniata $\left(X^{2}=3.2, d f=5, P=0.668\right)$, with the number of juveniles being too small for any statistical analysis.

Overall, cement (29.7\% of the sightings) and grass (29.8\%) were the substrates where lizards (all pooled species) were more frequently observed, followed by trees $(12.7 \%)$, bushes $(10.3 \%)$, sand $(7.8 \%)$ and stonepiles $(0.4 \%)$.

Substrates were used in relation to their relative availability by $A$. agama, but not by $T$. quinquetaeniata and $H$. angulatus (Table 4), showing that the former species was more a substratum type generalist than the two latter species. 
Table 4

Correlation values between substratum type availability and number of individuals observed in each substratum type at Baguida (Lomé), Togo. Statistically significant P-values would indicate generalism in substratum type usage by lizards. Significance is in boldface.

\begin{tabular}{|lll|}
\hline & Pearson's corr. Coeff. (R) & P \\
\hline A. agama males & 0.915 & $<0.01$ \\
\hline A. agama females & $\mathbf{0 . 9 7 9}$ & $<0.0001$ \\
\hline A. agama juveniles & $\mathbf{0 . 8 9 6}$ & $\mathbf{0 . 0 1 5 6}$ \\
\hline T. quinquetaeniata males & $\otimes 0.526$ & 0.283 \\
\hline T.quinquetaeniata females & $\otimes 0363$ & 0.479 \\
\hline T. quinquetaeniata juveniles & sample too small & \\
\hline Hemidactylus sp. & 0.370 & 0.470 \\
\hline
\end{tabular}

A nMDS analysis, with cement and grass being placed along the Component 1 (positive values) and trees, bushes and stone piles along Component 2 (negative values), revealed that $T$. quinquetaeniata resulted positioned towards high positive values of Component 1 and negative values of Component 2 , whereas $A$. agama at negative values of both Component 1 and 2 , and $H$. angulatus at negative values for Component 2 but highly positive values for Component 2 (Fig. 3). In this analysis, Component 1 explained $77.02 \%$ of the whole variance and Component 2 explained $22.35 \%$. The three species were also clearly spaced apart in the multidimensional space, with $A$. agama being very close to the habitat availability centroid, in a PCA diagram (Fig. 4). In both analyses, Hemidactylus sp. centroid was spaced far away from that of the other two species within the multidimensional space.

\section{Suburban lizards: vertical niche resource use}

The raw data on the distribution of lizard sightings by vertical height from the ground are given in Table 5. As for $A$. agama, males had much higher niche breadth $(B=4.46)$ than females $(B=2.41)$ and juveniles $(B=2.03)$. This difference was due to the fact that males $(1)$ used more frequently perches at $>101 \mathrm{~cm}$ height ( $26.4 \%$ of observed individuals) than females $(7.4 \%)$ or juveniles $(2.9 \%)$, and (2) they were observed more frequently at $10-50 \mathrm{~cm}$ height, whereas females and juveniles mostly on ground (Fig. 5), Thus, males usually perched higher than females and juveniles and overall, the differences between the three groups of individuals were statistically significant $\left(\chi^{2}\right.$ test, $\left.\mathrm{P}<0.001\right)$. On the other hand, in $T$. quinquetaeniata the three groups of individuals did not differ significantly $\left(\chi^{2}\right.$ test, $\left.P<0.001\right)$, with all of them being found essentially on ground (Fig. 6). However, also in this species the males exhibited a wider niche breadth $(B=3.26)$ than females $(B=1.82)$ and juveniles $(B=1.56)$.

Table 5

Raw data of the lizard sightings, divided by species and by height from the ground, at Baguida (Lomé), Togo.

\begin{tabular}{|c|c|c|c|c|c|c|c|}
\hline Species & Population category & on ground & $10-50 \mathrm{~cm}$ & $51-100 \mathrm{~cm}$ & $101-150 \mathrm{~cm}$ & $151 \mathrm{~cm}$ or more & Total \\
\hline Agama agama & males & 19 & 27 & 18 & 15 & 8 & 87 \\
\hline Agama agama & females & 70 & 41 & 8 & 5 & 3 & 127 \\
\hline Agama agama & juveniles & 86 & 44 & 4 & 4 & 0 & 138 \\
\hline Trachylepis quinquetaeniata & males & 21 & 7 & 8 & 6 & 2 & 44 \\
\hline Trachylepis quinquetaeniata & females & 44 & 15 & 3 & 1 & 1 & 64 \\
\hline Trachylepis quinquetaeniata & juveniles & 11 & 2 & 1 & 0 & 0 & 14 \\
\hline Trachylepis maculilabris & & 2 & 0 & 0 & 0 & 0 & 2 \\
\hline Trachylepis perrotetii & & 7 & 1 & 0 & 0 & 0 & 8 \\
\hline Hemidactylus sp. & & 9 & 18 & 32 & 51 & 16 & 126 \\
\hline Chamaeleo gracilis & & 0 & 0 & 1 & 0 & 0 & 1 \\
\hline
\end{tabular}

\section{Suburban lizards: simulations study}

Horizontal niche resource use.-- As for the substratum type use by lizards, the mean observed overlap between pairs of species was 0.625 . The mean of the simulated overlaps with RA3 was 0.365 (variance of simulated indices $=0.0089$; random seed $=1942475120)$, with $P($ observed $<=$ expected $)=0.983$ and $P($ observed $>=$ expected $)=0.017$. Using RA2, the mean of the simulated overlaps was 0.545 (variance of simulated indices $=0.0125 ;$ random seed $=$ -523877646), with $\mathrm{P}$ (observed $<=$ expected $)=0.753$ and $\mathrm{P}$ (observed $>=$ expected $)=0.247$. Thus, RA3 differed significantly from RA2 in that it showed a nonrandom preference for same substratum types by the whole lizard community, whereas there was no preference according to the latter algorithm, with the substratum type selection being random.

Vertical niche resource use.-The mean observed overlap between pairs of species was 0.641 . Using RA3, the mean of the simulated overlaps was 0.421 (variance of simulated indices $=0.00156$; random seed $=956343435)$, with $\mathrm{P}$ (observed $<=$ expected $)=0.999$ and $\mathrm{P}($ observed $>=$ expected $)=0.001$. With RA2, the mean of the simulated overlaps was 0.560 (variance of simulated indices $=0.00178$; random seed $=1521330926)$, with $P($ observed $<=$ expected) $=0.976$ 
and $\mathrm{P}$ (observed $>=$ expected $)=0.024$. In this case, both RA3 and RA2 gave consistent results, showing that there was a non-random preference for same height category by the whole lizard community.

\section{Discussion}

\section{General community characteristics along the habitat gradient}

Although not methodological consistent across habitat types, our study revealed that along the FSS gradient (i) there was a clearly higher species richness in the forest than in the savannah and suburbs, and that (ii) the three communities were quite taxonomically distinct. Thus, there was a "forest-specific" assemblage of species (including e.g. Varanus ornatus) and lowly diverse assemblages in savannahs (including e.g. Varanus exanthematicus) (Fig. 7) and suburbs, mostly characterized by ecological generalists with wide habitat tolerances. Both these diversity patterns were not unexpected (McKinney 2008). Concerning pattern (i), there is wide available literature showing that lizard communities are significantly more species-rich in tropical forests than in more open or degraded environments (Lewin et al. 2016), the same as generally observed in both vertebrates and invertebrates (e.g., Basset et al. 2008; Watling and Donnelly 2008). For instance, in the Philippines Supsup et al. (2020) found that higher species richness was found in secondary forests than in mixed-use agricultural areas. Since habitat heterogeneity is an important predictor in explaining lizard richness in Africa (Lewin et al. 2016), it is likely that the multiple microniches available in the hilly forests of the Togo hills may explain the much higher species richness that we observed therein in comparison with savannah and suburban habitats of the same study region.

Concerning pattern (ii), the fact that we observed habitat-specific assemblages of lizards at our study area mirrors observations from Brazilian Cerrado lizard communities (Nogueira et al. 2009). In the Brazilian Cerrado, in fact, habitat-specialists with patchy distributions in the forest-savannah-plantation mosaics create habitat-structured lizard assemblages with faunal overlap between forest and savannah being limited and forested versus open areas acting as mutual barriers to lizard distribution (Nogueira et al. 2009). In our study case, the taxonomical composition of the savannah assemblage was similar as that of the suburban habitat (although in the savannah we also observed Agama sankaranica and a few other species), thus suggesting that there is no clear barrier acting against lizard distribution between savannah and suburban areas in southern Togo.

The species richness reduction from forest to urban areas may also be interpreted as an effect of habitat loss on forest-specialists (Turner 1996; Lea et al. 2003; Edwards et al. 2013; Decena et al. 2020). Indeed, studies from tropical Africa have revealed that forest loss (by slash-and-burn shifting cultivations or by direct tree cutting) at the local scale produced a considerable reduction in the species richness of lizards (Akani et al. 2018). In a Niger Delta area, the number of sympatric lizards species was 9 in a unburnt forest patch, whereas it was just 2 in a nearby forest patch up to 12-16 months after fire (Akani et al. 2018). However, at the scale of southern Togo, the Dahomey Gap savannahs, albeit of likely anthropogenic origin, are there since few thousands years (XXXystemat; see Salzmann and Hoelzmann 2005). Thus, it is likely that the lower species richness of savannah lizard assemblages was due more to broad historical events and geographical/climatological reasons (Salzmann and Hoelzmann 2005) than to local-scale recent habitat loss.

\section{Suburban lizards: analysis of community structure and niche characteristics}

Our data revealed interspecific differences in both substratum type preferences and vertical spatial niche, but with no evidence of a mathematical structure consistent with a nonrandom niche partitioning pattern, and hence with a competitively assembled community structure. Instead, we detected a nonrandom "clustered" distribution of the various species along the available resource categories. Therefore, the main conclusion of our study is that species-specific preferences instead of community-driven mechanisms are more likely to explain the observed patterns at the study area.

Thus, we found no support for the hypothesis that lizards, as they can increase net energy gain from careful thermoregulation and hence selection of appropriate basking substrates, can compete for, and exclude potential competitors from, optimum basking sites (e.g.

Huey and Slatkin 1979). When interspecific competition cannot be advocated, the proximate external ecophysiological constraints are often considered the drivers of species-specific differences in niche characteristics (Barbault 1988; Barbault and Stearns 1991). In our case, thermal constraints pushing the selection of given substratum types for lizard basking (Huey and Slatkin 1979; Hailey 1982; Huey 1991) are unlikely to explain the observed patterns, as the study area has a tropical climate with ambient temperatures constantly ranging $27-32^{\circ} \mathrm{C}$ all throughout the year (https://it.climatedata.org/XXXystem/togo/maritime-region/lome-764237/). Interspecific differences in substratum type uses due for foraging reasons are also unlikely as the various species have a relatively similar insectivorous diet: at the study area, the diet of $A$. agama consisted mainly of Coleoptera adults and Formicoidea (Akani et al. 2013) and that of T. quinquetaeniata of Coleoptera adults and larvae, Lepidoptera adults and larvae and Formicidae (Dendi et al. 2019). For Hemidactylus sp. we do not have data for Lomé, but in a urban population from Port Harcourt (Nigeria) the diet was composed mainly by Lepidoptera adults and Formicoidea (Amadi et al. 2020a). In this latter species, however, the use of cement and elevated heights are likely linked to the need to exploit artificially lighted spots for optimal foraging over the insects that are attracted by night around electric bulbs (Amadi et al. 2020a). The same strategy was also employed by A. agama in Nigeria (Amadi et al. 2021), but in Lomé we never observed any shifts from diurnal to nocturnal foraging activity in contrast with the Nigerian conspecifics (Amadi et al. 2020b, 2021), whereas dietary shifts have been observed in other tropical lizards from urban environments (Balakrishna et al. 2016). Thus, we suggest that antipredatory reasons may be behind the species-specific substratum type selection and the height of perches, given that predation risk is well known to be a crucial determinant of community structuring of tropical communities (e.g., Pianka 1973, 1986; Poulin et al. 2001; Olsson et al. 2005, Reyes-Olivares et al. 2020). We also noticed that the artificial substratum (cement) was predominantly used by both $A$. agama and Hemidactylus $\mathrm{sp}$. In this regard, our data mirror other studies showing that lizards in urban areas use artificial substrates a large proportion of the time, and that these substrates tend to be broader than substrates in natural forest (Winchell et al. 2016; Amadi et al. 2020a, 2020b).

Intraspecific differences in the two species for which we collected such data ( $A$. agama and T. quinquetaeniata) were minor, but $A$. agama males tended to select higher perches than females and juveniles. This positive selection for elevated perches is likely related to the complex hierarchic structure of the $A$. agama groups, with dominant males often XXXystematic adult females from higher height (Anibaldi et al. 1998). 


\section{General considerations on lizard communities in tropical cities}

It is well known that urbanization, involving the conversion of natural habitats into human-modified ecosystems, usually reduce both the diversity and the abundance of indigenous animal communities, up to leading to the extinction of some species or even facilitating the establishment of non-indigenous communities in cities and towns (Hamer and McDonnell 2010). So, the general observations that we made (i.e. a reduced species richness in the suburban habitat of the FSS gradient) is not surprising. However, as mentioned above, our study also suggests that the lizard species used the available resources in a clustered way within the suburban habitat in Lomé. Whereas many studies analyzed reptile assemblages in secondary forests and altered habitats (e.g., Luya et al. 2008), the data available in the literature with regard to communities of lizards (or other reptiles) in tropical cities are relatively few and based on different methodologies from ours, and so comparisons with our study are not straightforward. However, in a snake community inhabiting a Brazilian city, Franca and Franca (2019) observed a clustered distribution for two species and dispersed distributions for eight species, and in a Indian city, Janiawati et al. (2016) demonstrated that the various reptilian species were clustered around water sources and vegetation cover patches. In fact, in urban fragments embedded in an "artificial matrix" hostile to the movement of individuals, most species tend to be concentrated into suitable microhabitats (and using clustered types of substratum) as extinction rates (stochastic or anthropogenic) are not compensated by colonization rates (Laurance et al. 2006a, 2006b; Salomão et al. 2019). Thus, we may conclude that lizard communities in tropical urban areas are (i) less species-rich than in the surrounding more natural habitats, (ii) usually clustered into specific habitat/substratum types (often artificial ones), and (iii) not assembled through competitive interactions. Further studies should verify the validity of these conclusions.

\section{Declarations}

Funding - This study was indirectly supported by funds provided from Mohamed Bin Zayed Species Conservation Fund and Turtle Conservation Fund.

Conflicts of interest - none

Ethics approval - not applicable

Consent for publication - All authors read and approved the final manuscript, and accepted to be co-authors in the published paper.

Availability of data and materials - Data will be available by the first author (LL) on request

Competing interests The authors declare no competing interests

Author contributions - LL generated the idea and designed the field protocol. All authors participated equally in data collection, analysis and writing of the various drafts. All authors agreed on the final submitted version of the manuscript.

\section{References}

1. Addai G, Baidoo PK (2013) The effects of forest destruction on the abundance, species richness and diversity of butterflies in the Bosomkese Forest Reserve, Brong Ahafo Region, Ghana. Journal of Applied Biosciences 64:4763-4772

2. Akani GC, Amadi N, Dendi D, Luiselli L (2018) Do community metrics vary in reptile communities from Niger Delta forests subjected to slash-and-burn agricultural practices? Afr J Ecol 56:1044-1048

3. Akani GC, Petrozzi F, Rugiero L, Segniagbeto GH, Luiselli L (2013) Effects of rainfall and geography on the comparative diets of eight rainbow lizard populations across Togo, Benin and Nigeria (West Africa). Amphibia-Reptilia 34:185-192

4. Amadi N, Gladstone GC, Wala C, Vignoli L, Ugbomeh A, Luiselli L (2020a) Habitat use and food habits of a gecko population in a west African suburban area. European Journal of Ecology 6:1-12

5. Amadi N, Belema R, Obodo CH, Dendi D, Chidinma A, Meek R, Luiselli L (2020b) Life in the suburbs: artificial heat source selection for nocturnal thermoregulation in a diurnally active tropical lizard. Web Ecol 20:161-172

6. Amadi N, Luiselli L, Belema R, Nyiwale GA, Wala C, Urubia N, Meek R (2021) From diurnal to nocturnal activity: a case study of night-light niche expansion in Agama agama lizards. Ethology Ecology \& Evolution DOI: 10.1080/03949370.2021.1883120

7. Anibaldi C, Luiselli L, Angelici FM (1998) Notes on the ecology of a suburban population of rainbow lizards in coastal Kenya. African journal of Ecology 36:199-206

8. Avila AC, Stenert C, Rodrigues ENL, Maltchik L (2017) Habitat structure determines spider diversity in highland ponds. Ecol Res 32:359-367

9. Balakrishna S, Batabyal A, Thaker M (2016) Dining in the city: dietary shifts in Indian rock agamas across an urban-rural landscape. Journal of Herpetology 50:423-428

10. Barbault R (1988) Body size, ecological constraints, and the evolution of life-history strategies. Evolutionary Biology, 1988:261-286

11. Barbault R, Stearns S (1991) Towards an evolutionary ecology linking species interactions, life-history strategies and community dynamics: An introduction. Acta Oecol 12:3-10

12. Basset $Y$, Missa O, Alonso A, Miller SE, Curletti G, De Meyer M, ... Wagner $T$ (2008) Changes in arthropod assemblages along a wide gradient of disturbance in Gabon. Conserv Biol 22:1552-1563

13. Clarke KR (1993) Non-parametric multivariate analysis of changes in community structure. Austral J Ecol 18:117-143 
14. Costa BM, Pantoja DL, Sousa HC, de Queiroz TA, Colli GR (2020) Long-term, fire-induced changes in habitat structure and microclimate affect Cerrado lizard communities. Biodivers Conserv 29:1659-1681

15. Decena SCP, Avorque CA, Decena ICP, Asis PD, Pacle B (2020) Impact of habitat alteration on amphibian diversity and species composition in a lowland tropical rainforest in Northeastern Leyte, Philippines. Sci Rep 10:1-15

16. Demenou BB, Doucet JL, Hardy OJ (2018) History of the fragmentation of the African rain forest in the Dahomey Gap: insight from the demographic history of Terminalia XXXYstem. Heredity 120:547-561

17. Dendi D, Segniagbeto GH, Di Vittorio M, Luiselli L (2019) Are diet diversity metrics influenced more by rainfall or by temperature in an Afrotropical Scincid Lizard? Ecol Res 34:68-73

18. Franca RA, Franca GR (2019) Spatial patterns of snake diversity in an urban area of north-east Brazil. Herpetol J 29:274-281

19. Freestone AL, Carroll EW, Papacostas KJ, Ruiz GM, Torchin ME, Sewall BJ (2020) Predation shapes invertebrate diversity in tropical but not temperate seagrass communities. J Anim Ecol 89:323-333

20. Edwards FA, Edwards DP, Hamer KC, Davies RG (2013) Impacts of logging and conversion of rainforest to oil palm on the functional diversity of birds in Sundaland. Ibis 155:313-326

21. Estrada A, Coates-Estrada R, Meritt D Jr (1993) Bat species richness and abundance in tropical rain forest fragments and in agricultural habitats at Los Tuxtlas. Mexico Ecography 16:309-318

22. Gotelli NJ, Entsminger EJ (2003) Ecosim: null model software for ecology. Aquired Intelligence Inc., New York

23. Gotelli NJ, Graves GC (1996) Null Models in Ecology. Smithsonian Institution Press, Washington, DC

24. Hailey A (1982) Choice of substrate and heating rate in Lacerta vivipara. British Journal of Herpetology 6:207-213

25. Hamer AJ, McDonnell MJ (2010) The response of herpetofauna to urbanization: inferring patterns of persistence from wildlife databases. Austral Ecol 35:568-580

26. Harper DAT (1999) Numerical palaeobiology. John Wiley and Sons, New York

27. Huey RB (1991) Physiological consequences of habitat selection. Am Nat 137:S91-S115

28. Huey RB, Slatkin M (1976) Costs and benefits of lizard thermoregulation. Q Rev Biol 51:363-384

29. Iloh AC, Schmidt M, Muellner-Riehl AN, Ogundipe OT, Paule J (2017) Pleistocene refugia and genetic diversity patterns in West Africa: Insights from the liana Chasmanthera dependens (Menispermaceae). PloS one 12(3):e0170511

30. Janiawati IAA, Kusrini MD, Mardiastuti A (2016) Structure and composition of reptile communities in human modified landscape in Gianyar Regency, Bali. HAYATI Journal of Biosciences 23:85-91

31. Khatiwada JR, Zhao T, Chen Y, Wang B, Xie F, Cannatella DC, Jiang J (2019) Amphibian community structure along elevation gradients in eastern Nepal Himalaya. BMC Ecol 19(1):1-11

32. Laurance WF, Nascimento H, Laurance SG, Andrade A, Fearnside PM, Ribeiro J (2006a) Rain forest fragmentation and the proliferation of successional trees. Ecology 87:469-482

33. Laurance WF, Nascimento H, Laurance SG, Andrade A, Ribeiro J, Giraldo JP, Lovejoy TE, Condit R, Chave J, D'Angelo S (2006b) Rapid decay of tree community composition in Amazonian forest fragments. Proc Natl Acad Sci USA 103:19010-19014

34. Lawlor LR (1980) Structure and stability in natural and randomly constructed competitive communities. Am Nat 116:394-408

35. Lea J, Politano E, Luiselli L (2003) Changes in the herpetofauna of a fresh water river in southern Nigeria, after 20 years of development. Russian Journal of Herpetology 10:191-198

36. Leaché AD, Oaks JR, Ofori-Boateng C, Fujita MK (2020) Comparative phylogeography of West African amphibians and reptiles. Evolution 74:716-724

37. Lewin A, Feldman A, Bauer AM, Belmaker J, Broadley DG, Chirio L, Itescu Y, LeBreton M, Maza E, Meirte D, Nagy ZT, Novosolov M, Roll U, Tallowin O, Trape J-F, Vidan E, Meiri S (2016) Patterns of species richness, endemism and environmental gradients of African reptiles. J Biogeogr 43:2380-2390

38. Luja VH, Herrando-Pérez S, González-Solís D, Luiselli L (2008) Secondary rain forests are not havens for reptile species in tropical Mexico. Biotropica 40:747-757

39. Magurran AE (1988) Ecological diversity and its measurement. Princeton University Press, Princeton

40. McKinney ML (2008) Effects of urbanization on species richness: a review of plants and animals. Urban Ecosystems 11:161-176

41. Nogueira C, Colli GR, Martins M (2009) Local richness and distribution of the lizard fauna in natural habitat mosaics of the Brazilian Cerrado. Austral Ecol 34:83-96

42. Nurminen L, Hellén N, Olin M, Tiainen J, Vinni M, Grönroos $M$, ... Lehtonen $H$ (2018) Fishing-induced changes in predation pressure by perch (Perca fluviatilis) regulate littoral benthic macroinvertebrate biomass, density, and community structure. Aquat Ecol 52:1-16

43. Olsson M, Wapstra E, Swan G, Snaith ERN, Clarke RON, Madsen T (2005) Effects of long-term fox baiting on species composition and abundance in an Australian lizard community. Austral Ecol 30:899-905

44. Palmeirim AF, Vieira MV, Peres CA (2017) Herpetofaunal responses to anthropogenic forest habitat modification across the neotropics: insights from partitioning $\beta$-diversity. Biodivers Conserv 26:2877-2891

45. Penner J, Augustin M, Roedel MO (2018) Modeling the spatial baseline for amphibian conservation in West Africa. Acta Oecol 94:31-40

46. Pianka ER (1973) The structure of lizard communities. Annu Rev Ecol Syst 4:53-74

47. Pianka ER (1986) Ecology and natural history of desert lizards. Princeton University Press, XXXystemati

Page $10 / 14$ 
48. Pillsbury FC, Miller JR (2008) Habitat and landscape characteristics underlying anuran community structure along an urban-rural gradient. Ecol Appl 18:1107-1118

49. Poulin B, Lefebvre G, Ibáñez R, Jaramillo C, Hernández C, Rand AS (2001) Avian predation upon lizards and frogs in a neotropical forest understorey. Journal of tropical Ecology 2001:21-40

50. Powell LL, Ames EM, Wright JR, Matthiopoulos J, Marra PP (2021) Interspecific competition between resident and wintering birds: experimental evidence and consequences of coexistence. Ecology 102(2):e03208

51. Reyes-Olivares C, Guajardo-Santibáñez A, Segura B, Zañartu N, Penna M, Labra A (2020) Lizard predation by spiders: A review from the Neotropical and Andean regions. Ecology Evolution 10:10953-10964

52. Salinas-Ramos VB, Ancillotto L, Bosso L, Sánchez-Cordero V, Russo D (2020) Interspecific competition in bats: state of knowledge and research challenges. Mammal Review 50:68-81

53. Salomão RP, Alvarado F, Baena-Díaz F, Favila ME, lannuzzi L, Liberal CN, Santos BA, Vaz-de-Mello FZ, González-Tokman D (2019) Urbanization effects on dung beetle assemblages in a tropical city. Ecol Ind 103:665-675

54. Salzmann U, Hoelzmann P (2005) The Dahomey Gap: an abrupt climatically induced rain forest fragmentation in West Africa during the late Holocene. The Holocene 15:190-199

55. Segniagbeto GH, Trape JF, Afiademanyo KM, Rödel MO, Ohler A, Dubois A, ... Luiselli L (2015) Checklist of the lizards of Togo (West Africa), with comments on XXXystematic, distribution, ecology, and conservation. Zoosystema 37:381-402

56. Shannon CE, Weaver W (1963) The mathematical theory of communication. University of Illinois Press, Urbana

57. Simpson EH (1949) Measurement of diversity. Nature 163:688

58. Supsup CE, Asis AA, Carestia UV Jr, Diesmos AC, Aldrin N, Mallari D, Brown RM (2020) Variation in species richness, composition and herpetological community structure across a tropical habitat gradient of Palawan Island. Philippines Herpetozoa 33:95-111

59. Turner IM (1996) Species loss in fragments of tropical rain forest: a review of the evidence. Journal of Applied Ecology 1996:200-209

60. Yeo K, Delsinne T, Konate S, Alonso LL, Aïdara D, Peeters C (2017) Diversity and distribution of ant assemblages above and below ground in a West African forest-savannah mosaic (Lamto, Côte d'Ivoire). Insectes Soc 64:155-168

61. Watling Jl, Donnelly MA (2008) Species richness and composition of amphibians and reptiles in a fragmented forest landscape in northeastern Bolivia. Basic Appl Ecol 9:523-532

62. Wellborn GA, Skelly DK, Werner EE (1996) Mechanisms creating community structure across a freshwater habitat gradient. Annu Rev Ecol Syst 27:337363

63. Winchell KM, Reynolds RG, Prado-Irwin SR, Puente-Rolón AR, Revell LJ (2016) Phenotypic shifts in urban areas in the tropical lizard Anolis cristatellus. Evolution 70:1009-1022

\section{Figures}

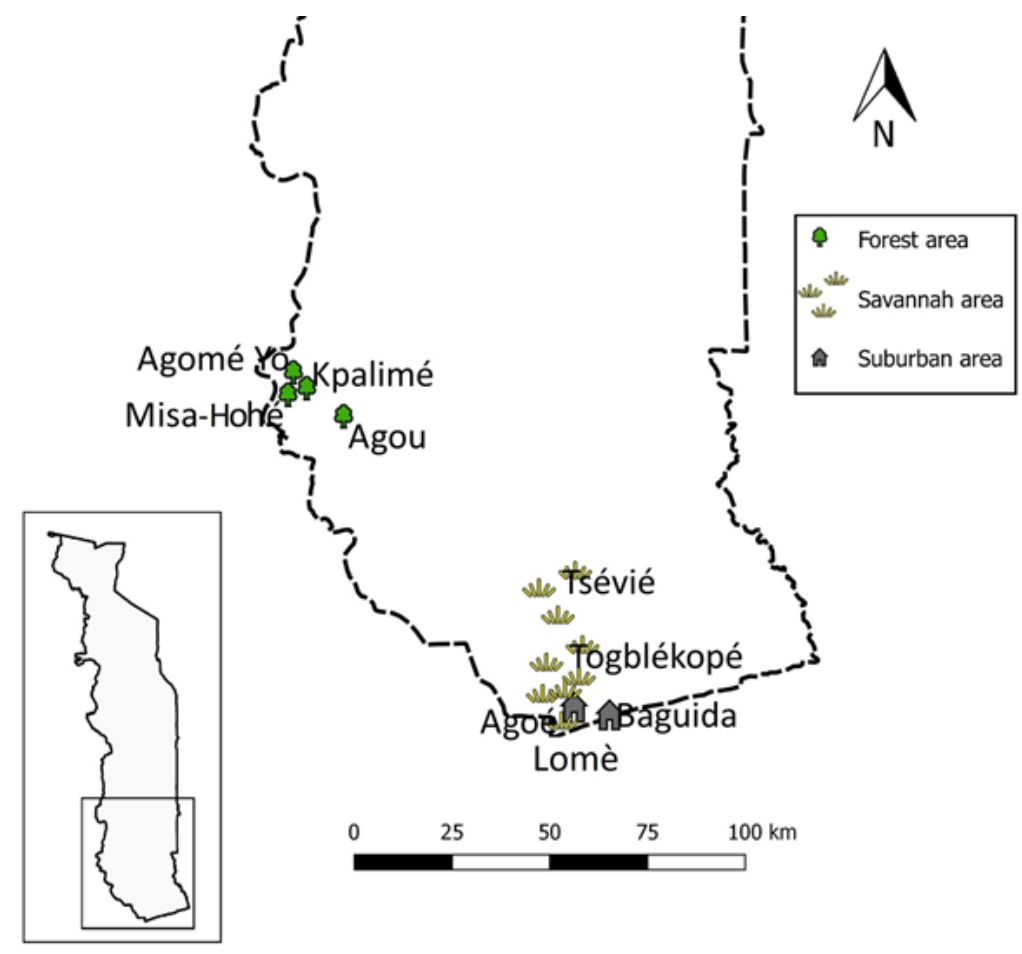

Page $11 / 14$ 


\section{Figure 1}

Map of southern Togo, showing the various study areas. Note: The designations employed and the presentation of the material on this map do not imply the expression of any opinion whatsoever on the part of Research Square concerning the legal status of any country, territory, city or area or of its authorities, or concerning the delimitation of its frontiers or boundaries. This map has been provided by the authors.

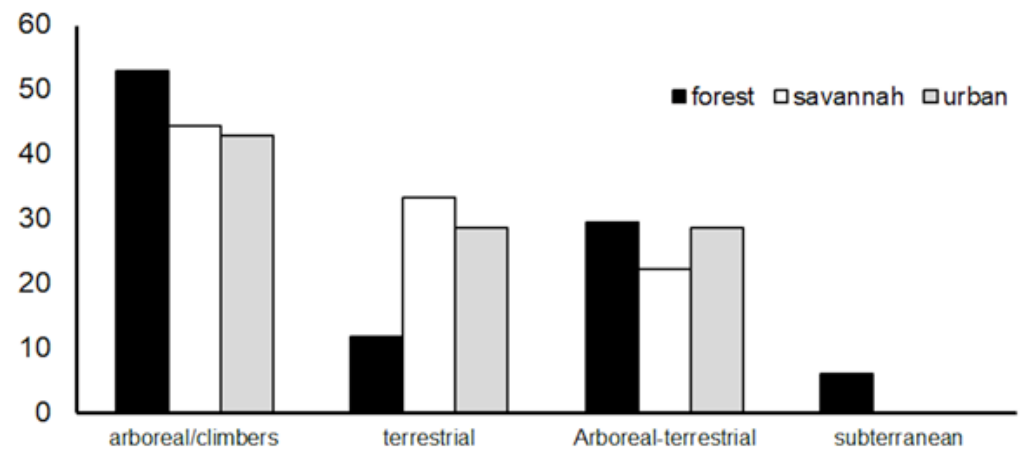

Figure 2

Distribution frequency of species by ecological niche (arboreal/climbers; arboreal-terrestrial; terrestrial; subterranean) across the forest-savannah-suburbs gradient. Sample sizes: forest $n=19$; forest-derived savannah $n=9$; suburban area $n=7$.

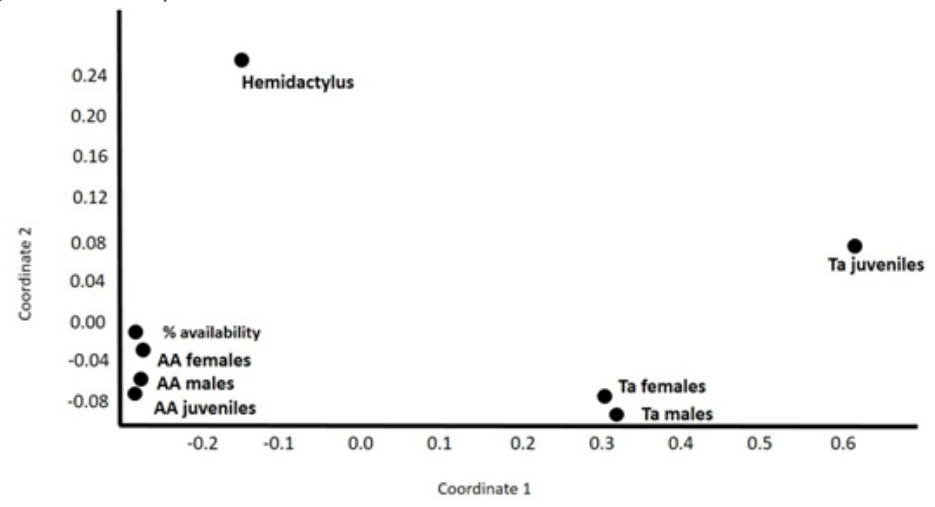

Figure 3

Non-metric multidimensional scaling (with COSINE as similarity measure) representing suburban lizard species in relation to their substratum use and availability in the field. In this graphic, cement and grass are placed along the Component 1 (positive values) and trees, bushes and stone piles along Component 2 (negative values). Component 1 explained $77.02 \%$ of the whole variance and Component 2 explained 22.35\%. Symbols: AA = Agama agama; Ta = Trachylepis quinquetaeniata.

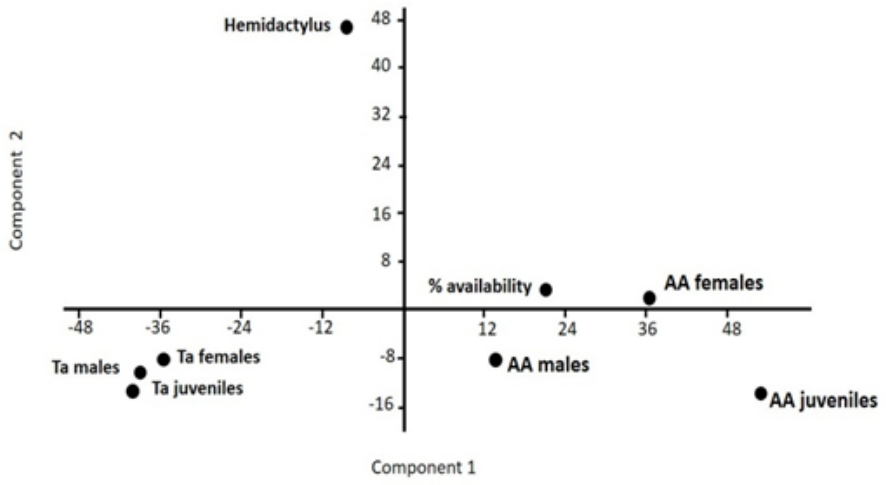

Figure 4

Diagram of a Principal Component Analysis arranging suburban lizard species in relation to their similarities in substratum use and in relation to the overall substratum type availability in the field. Symbols: AA = Agama agama; Ta = Trachylepis quinquetaeniata.

Page 12/14 


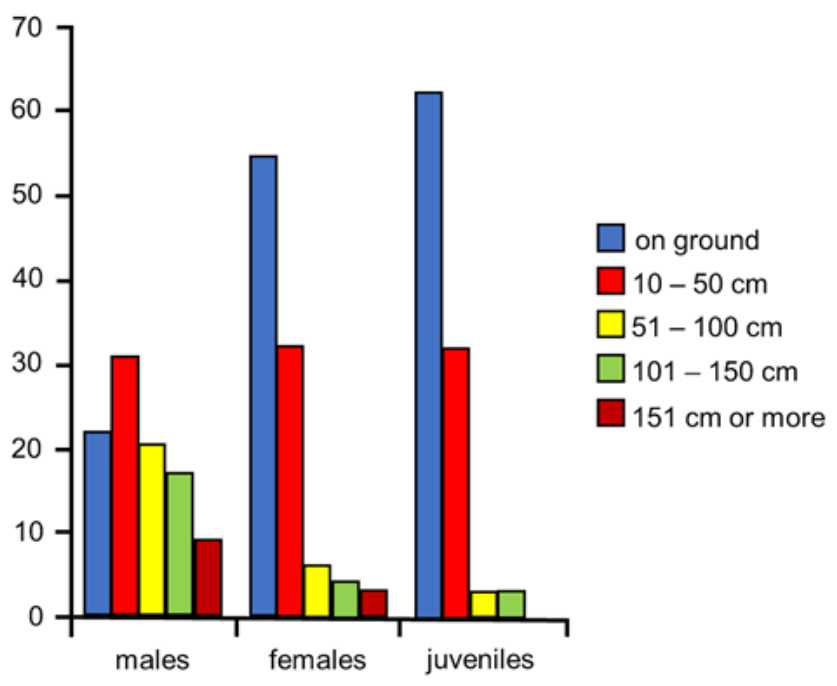

Figure 5

Percentage of suburban Agama agama individuals observed at the various height categories from the soil. Sample sizes: $m a l e s, n=87 ;$ females, $n=127$; juveniles, $n=138$.

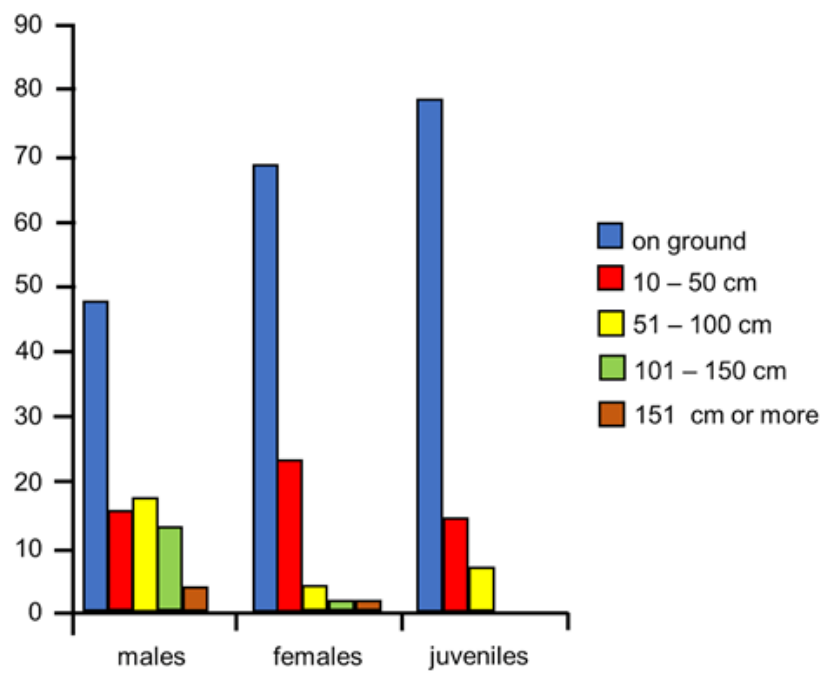

Figure 6

Percentage of suburban Trachylepis quinquetaeniata individuals observed at the various height categories from the soil. Sample sizes: males, $\mathrm{n}=44 ;$ females, $\mathrm{n}=64$; juveniles, $\mathrm{n}=14$. 

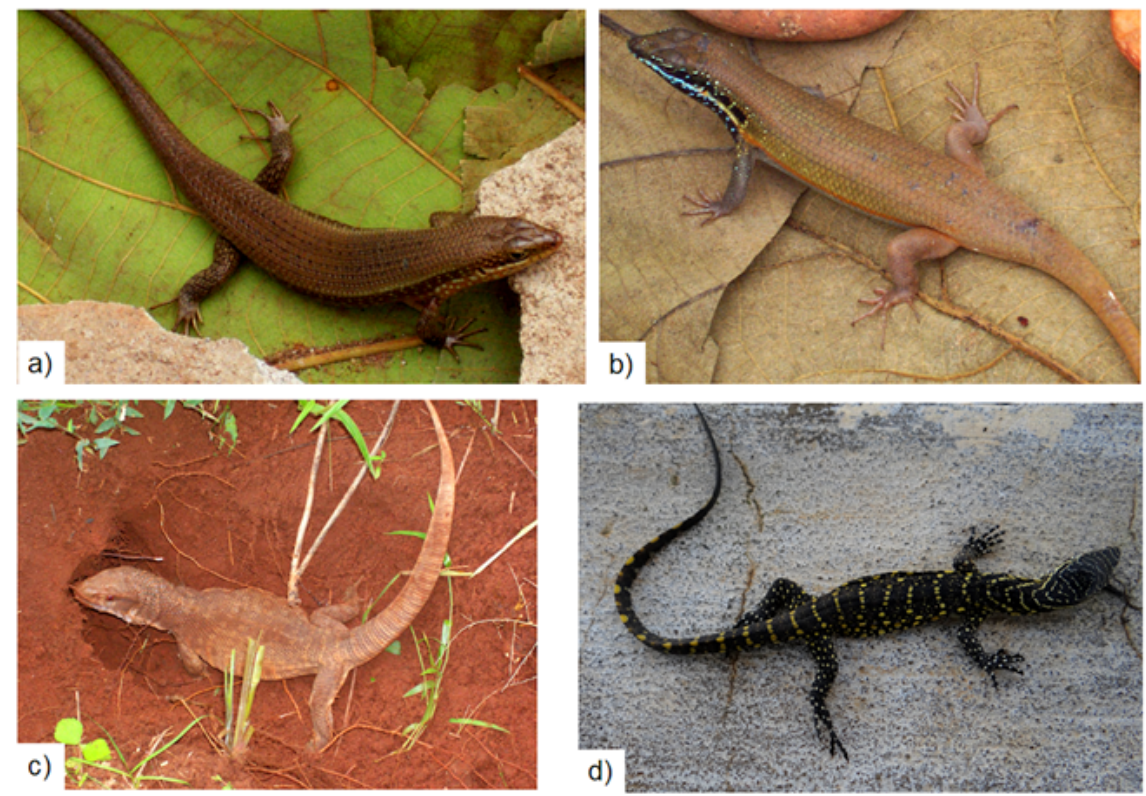

\section{Figure 7}

Some remarkable species observed at the study area in south-western Togo: (a) Trachylepis perrotetii, (b) Trachylepis quinquetaeniata, (c) Varanus exanthematicus, (d) Varanus ornatus.

\section{Supplementary Files}

This is a list of supplementary files associated with this preprint. Click to download.

- FigS1.png 